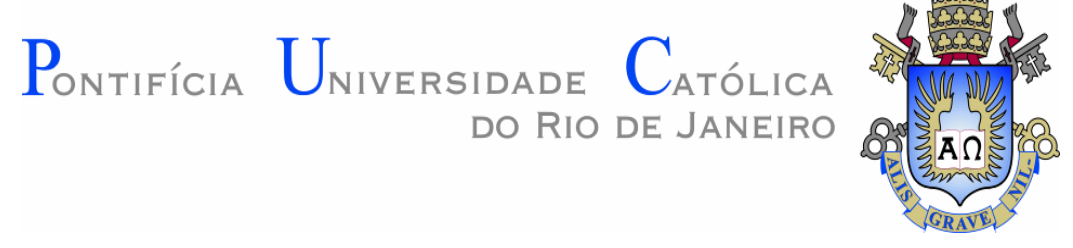

Marta Nidia Varella Gomes Maia

\title{
CURRÍCULO DA EDUCAÇÃO INFANTIL E DATAS COMEMORATIVAS: O que dizem profissionais e crianças
}

Tese de Doutorado

Tese apresentada ao Programa de PósGraduação em Educação da PUC-Rio, como requisito parcial para obtenção do título de Doutora em Educação.

Orientadora: Prof. Sonia Kramer

Rio de Janeiro Abril de 2016 


\title{
Currículo da Educação Infantil e Datas Comemorativas: 0 que dizem profissionais e crianças.
}

Tese apresentada como requisito parcial para obtenção do grau de Doutor pelo Programa de Pós-Graduação em Educação do Departamento de Educação do Centro de Teologia e Ciências Humanas da PUC-Rio. Aprovada pela Comissão Examinadora abaixo assinada.

\author{
Profa. Sonia Kramer \\ Orientadora \\ Departamento de Educação - PUC-Rio \\ Prof ${ }^{\mathrm{a}}$. Maria Inês G. F. Marcondes de Souza \\ Departamento de Educação - PUC-Rio \\ Prof ${ }^{\mathrm{a}}$. Zena Winona Eisenberg \\ Departamento de Educação - PUC-Rio \\ Profa . Flávia Miller Naethe Motta \\ UFRRJ \\ Prof ${ }^{\circ}$. Aristeo Gonçalves Leite Filho \\ UERJ

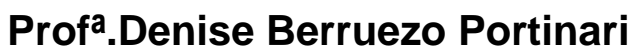 \\ Coordenadora Setorial do Centro \\ de Teologia e Ciências Humanas \\ PUC-Rio
}

Rio de Janeiro, 12 de abril de 2016. 
Todos os direitos reservados. É proibida a reprodução total ou parcial do trabalho sem autorização da universidade, da autora e do orientador.

\section{Marta Nidia Varella Gomes Maia}

Graduada em Pedagogia pela Universidade Federal Fluminense (2000) com especialização em Alfabetização das Crianças das Classes Populares (UFF, 2003) e especialização em Saúde Mental e Desenvolvimento da Criança e do Adolescente (CESANTA- RJ, 2006), Mestre em Educação pela PUC-Rio (2011). Atuou como professora de Educação Infantil e Ensino Fundamental na rede privada e na rede estadual. Na Rede Municipal de Niterói trabalhou com Educação de Crianças com Necessidades Especiais, com Educação de Jovens e Adultos, respondeu pela Coordenação de Educação Infantil, atua como professora de Educação Infantil e Supervisora Pedagógica na mesma rede.

Ficha Catalográfica

Maia, Marta Nidia Varella Gomes

Currículo da educação infantil e datas comemorativas : o que dizem profissionais e crianças / Marta Nidia Varella Gomes Maia ; orientadora: Sonia Kramer. - 2016. 191 f.; $30 \mathrm{~cm}$

Tese (doutorado)-Pontifícia Universidade Católica do Rio de Janeiro, Departamento de Educação, 2016.

Inclui bibliografia

1. Educação - Teses. 2. Currículo. 3. Educação infantil. 4. Datas comemorativas. 5. Professores. 6. Crianças. I. Kramer, Sonia. II. Pontifícia Universidade Católica do Rio de Janeiro. Departamento de Educação. III. Título. 
Dedico essa tese a cada um que, sabendo-se inacabado, mantém a esperança de fazer-se todo dia um pouco melhor. 


\section{Agradecimentos}

A vida não para enquanto a gente faz doutorado, diz o querido professor Marcelo Andrade. Ela não parou mesmo, pelo contrário, ela acelerou, se complexificou, se complicou. Foram muitos momentos difíceis por variadas razões, mas também foram muitos momentos de superação e aprendizagem. Em todos tive companhia, ajuda, apoio, amor, amizade e por isso, agradeço:

A Deus por ter me concedido viver tudo isso exatamente como foi, por mostrar todos os dias o quanto ainda preciso viver e aprender.

A papai e a mamãe por terem chegado aos oito e assim me darem a vida, essa vida vivida com eles, amada por eles e amando com eles.

Aos homens da minha vida: Maurício, Vinícius e Lucas; amores, companheiros, cúmplices, desafios, orgulhos, admiração.

Aos amigos queridos que tanto me apoiaram, me ouviram, me orientaram, me divertiram, me inspiraram. Nessa caminhada encontrei tantos e a gratidão é tão grande que já não poderia nomeá-los nestas páginas.

À PUC-Rio e seus funcionários, por todo apoio, acolhimento. Nomeá-los seria uma grande lista que começaria no estacionamento, passaria pela lanchonete, pela biblioteca, e chegaria ao Departamento de Educação. Neste último onde ainda encontrei socorro e orientação cada vez que me perdia nas datas, formulários...

Aos professores, mestres queridos, que tão pacientes foram com as minhas inquietações e tanto me ensinaram. Estudar com essas referências assusta e instiga.

Aos integrantes do grupo de pesquisa INFOC, com os quais tenho vivido uma jornada emocionante, apaixonante, de investigar a vida com lentes teóricas. Em especial desejo agradecer à Sílvia Néli, que além de todo o carinho que sempre dispensa a todos, foi uma grande colaboradora na reta final da escrita da tese. Sua orientação, seus toques, suas dicas foram essenciais, sem contar o afeto que embebia cada palavra cuidadosamente dita, cada anotação feita. 
Aos colegas das diferentes turmas que estudei. Encontros felizes, companheiros de angústias, descobertas, alegrias, risos, cafés, pizzas, trânsito.

Aos gestores da rede e das escolas pesquisadas por terem me recebido tão amavelmente.

Aos educadores de ambas as escolas, em particular às professoras participantes da pesquisa, por terem me permitido transitar por suas práticas e ocupar o espaço de suas salas.

Às crianças, queridas, incríveis, desafiadoras, que participaram da pesquisa e tanto me oportunizaram aprender a partir delas.

Às diretoras, amigas e companheiras das escolas Professor André Trouche e Infante Dom Henrique que muito me apoiaram nesse percurso.

Aos professores Antônio Flávio Moreira, Aristeo Leite Filho, Maria Fernanda Nunes e Zilma de Oliveira, pelas entrevistas concedidas, pela disponibilidade e carinho com que o fizeram.

Às professoras Maria Inês Marcondes e Zena Eisenberg pelas contribuições e orientações dadas nas qualificações I e II.

Aos admirados professores que compõem essa banca, Aristeo Leite Filho, Flavia Naethe Motta, Maria Inês Marcondes e Zena Eisenberg, pela gentileza e disponibilidade de estarem aqui.

À minha querida orientadora, Sonia Kramer. Obrigada por dividir e multiplicar seu conhecimento, por ser firme quando necessário e doce quando imprescindível. Obrigada por me orientar para além da tese, por ter acolhido minha dor e ajudado a transformá-la em escrita. Obrigada por não me deixar desistir quando já não tinha ânimo, por clarear meu caminho quando eu já não via luz.

Ao CNPq e à PUC-Rio, pelos auxílios concedidos, sem os quais este trabalho não poderia ter sido realizado. 


\section{Resumo}

Maia, Marta Nidia Varella Gomes; Kramer, Sonia. Currículo da Educação Infantil e Datas Comemorativas: O que dizem profissionais e crianças. Rio de Janeiro, 2016. 191p. Tese de Doutorado - Departamento de Educação, Pontifícia Universidade Católica do Rio de Janeiro.

Currículo da Educação Infantil e Datas Comemorativas: O que dizem profissionais e crianças, tem como objetivo conhecer e compreender o que falam sobre os currículos da Educação Infantil crianças e adultos que atuam em escolas exclusivas de Educação Infantil e escolas de Ensino Fundamental que têm turmas de Educação Infantil. As crianças foram ouvidas em atividades livres, em atividades dirigidas pelas professoras e em rodas de conversa específicas da pesquisa. Os profissionais foram ouvidos em conversas informais e em entrevista coletiva. Convivem concepções conservadoras e atualizadas de Infância e Educação Infantil que repercutem nas práticas. Coexistem concepções e práticas diferenciadas na rede pesquisada que podem vir a trazer novos caminhos para a Educação Infantil. O currículo centrado em datas está presente, mas não apenas como algo natural e intocável. A tese está organizada em quatro capítulos. O primeiro expõe a construção histórica e ideológica da qual deriva o currículo orientado por datas comemorativas. O segundo capítulo apresenta as entrevistas realizadas com quatro especialistas das áreas de Currículo e Educação Infantil para compreender as condições que levaram a inserção e permanência desse currículo. No terceiro capítulo são apresentados autores que sustentam as opções teóricometodológicas da pesquisa; da perspectiva histórico-cultural, Mikhail Bakhtin e Walter Benjamin, da Sociologia da Infância Qvortrup, Sarmento, Corsaro e da Filosofia, Kohan; os caminhos percorridos, a rede de ensino pesquisada, as escolas e seus sujeitos. O quarto capítulo traz a palavra das crianças e adultos, a observação, as rodas de conversa com as crianças, a entrevista coletiva com os profissionais. As conclusões e apontamentos reafirmam a potência de cada sujeito e que se realiza no encontro com outro, no processo de alteridade que nos constitui à medida que nos abrimos a esse encontro infinitamente formativo e inconcluso.

\section{Palavras-chave}

Currículo; Educação Infantil; Datas Comemorativas; professoras; crianças. 


\section{Abstract}

Maia, Marta Nidia Varella Gomes; Kramer, Sonia (Advisor). Curriculum from kindergarten and Commemorative Dates: What they say professionals and children. Rio de Janeiro, 2016. 191p. Doctoral Thesis Departamento de Educação, Pontifícia Universidade Católica do Rio de Janeiro.

Curriculum of Early Childhood Education and Commemorative Dates: What they say professionals and children, aims to know and understand what they say about the curriculum from kindergarten children and adults working in exclusive schools for early childhood education and schools of elementary school who have Early Childhood Education classes. The children were heard in free activities, in activities directed by teachers and specific discussion of the research wheels. The professionals were heard in informal talks and a news conference. Live conservative and current conceptions of childhood and childhood education that impact in practice. Coexisting concepts and differentiated practices in the research network that may bring new ways for Early Childhood Education. The curriculum centered on dates is present, but not just as something natural and untouchable. The thesis is organized into four chapters. The first exposes the historical and ideological construction which derives the curriculum oriented holidays. The second chapter presents interviews with four specialists in the areas of curriculum and Early Childhood Education to understand the conditions that led to the inclusion and permanence of this curriculum. In the third chapter presents authors who support the theoretical and methodological choices of the research; culturalhistorical perspective, Mikhail Bakhtin and Walter Benjamin, the sociology of childhood Qvortrup, Sarmento, Corsaro and philosophy, Kohan; the paths taken, the researched school system, schools and their subjects. The fourth chapter brings the word of children and adults, observation, conversation circles with children, the press conference with professionals. The conclusions and notes reaffirm the power of each subject, which takes place in the encounter with the other, the otherness process that constitutes us as we open this meeting infinitely training and inconclusive.

\section{Keywords}

Curriculum; Child education; Commemorative dates; teachers; children. 


\section{Sumário}

Introdução

1 - Nos meandros da pesquisa: calendário, currículo e Educação

Infantil.

1.1 Calendário Civil e Religioso: a institucionalização da tradição ....16

1.2 O Currículo: entre os sujeitos e o conhecimento ........................23

1.3 Educação Infantil: direitos e práticas .......................................37

2 - Currículo da Educação Infantil - Conversas com especialistas .........44

2.1 Os entrevistados: trajetórias e produções ...............................46

2.2 As entrevistas ................................................................ 50

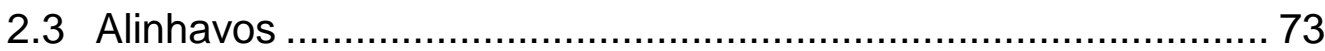

3 - Sobrevoo e trilhas da pesquisa: caminhos para olhar as práticas da Educação Infantil

3.1 Processo de Pesquisa ............................................................78

3.2 Rede de Ensino e Currículo: uma visão a partir dos Projetos Políticos Pedagógicos 91

3.3 Escolas e Professoras pesquisadas .100

4 - No cotidiano da escola: o currículo na palavra de crianças e adultos

4.1 Observação das práticas: Entre a vida e as tarefas 115

4.2 Ouvindo as crianças

4.3 "As coisas em que eu acredito"- A entrevista coletiva 141

4.4 No encontro da palavra de crianças e adultos: o currículo 151

4.5 Currículos: Conservadores ou Atualizados e suas Ambivalências 162

5 - Concluindo. Apontando caminhos. Deixando rastros. 166

6 - Referências bibliográficas

Anexos .175

Anexo 1 - Termo de Consentimento Livre e Esclarecido

Anexo 2 - Roteiro A de entrevista com especialistas

Anexo 3 - Roteiro B de entrevista com especialistas

Anexo 4 - Roteiro de entrevista coletiva

Anexo 5 - Ficha de Identificação

Anexo 6 - Proposta Pedagógica do Município 


\section{Lista de siglas}

ANDE - Associação Nacional de Docentes.

ANPEd - Associação Nacional de Pesquisa e Pós-Graduação em Educação.

$\mathrm{BH}$ - Belo Horizonte.

CAPES - Coordenação de Apoio à Pesquisa e Ensino Superior.

CBPE - Centro Brasileiro de Pesquisas Educacionais.

CEDES - Centro de Estudos Educação e Sociedade.

CIEP - Centro Integrado de Educação Pública.

CNE - Conselho Nacional de Educação.

$\mathrm{CNPq}$ - Conselho Nacional de Desenvolvimento Científico e Tecnológico

COEDI - Coordenação Geral de Educação Infantil

DCNEI - Diretrizes Curriculares Nacionais para a Educação Infantil.

DR - Dupla Regência.

ECA - Estatuto da Criança e do Adolescente.

EI - Educação Infantil.

EIPP - Grupo de Pesquisa Educação Infantil e Políticas Públicas.

EPB - Estudos de Problemas Brasileiros.

ETD - Educação Temática Digital.

EVA - Etil Vinil Acetato

FAPESP - Fundação de Apoio à Pesquisa do Estado de São Paulo.

FONAPER - Fórum Nacional Permanente do Ensino Religioso.

FUNABEM - Fundação Nacional do Bem-Estar do Menor.

FUNDEB - Fundo de Manutenção e Desenvolvimento da Educação Básica e de

Valorização dos Profissionais da Educação.

IBGE - Instituto Brasileiro de Geografia Estatística.

IDH - Índice do Desenvolvimento Humano.

INEP - Instituto Nacional de Estatísticas e Pesquisa.

INFOC - Grupo de Pesquisa Infância, Formação e Cultura.

LDB - Lei de Diretrizes e Bases.

MEC - Ministério da Educação.

MIEIB - Movimento Interfóruns de Educação Infantil do Brasil.

MOBRAL - Movimento Brasileiro de Alfabetização.

NEE - Necessidades Educacionais Especiais.

PCN's - Parâmetros Curriculares Nacionais.

PCNER - Parâmetros Curriculares Nacionais do Ensino Religioso.

PIBID - Programa Institucional de Bolsa de Iniciação à Docência.

PNLD - Programa Nacional do Livro Didático.

PPP - Projeto Político Pedagógico.

PROALE - Programa de Alfabetização e Leitura.

PUC/Rio - Pontifícia Universidade Católica do Rio de Janeiro.

RBE - Revista Brasileira de Educação.

RCNEI - Referenciais Curriculares Nacionais para a Educação

Infantil. Scielo - Scientific Electronic Library Online SEMED -

Secretaria Municipal de Educação.

SENAC - Serviço Nacional do Comércio.

SESI - Serviço Social da Indústria.

SME/RJ - Secretaria Municipal de Educação do Rio de Janeiro.

SPC - Serviço de Proteção ao Crédito.

UERJ - Universidade Estadual do Rio de Janeiro.

UFF - Universidade Federal Fluminense.

UFRJ - Universidade Federal do Estado do Rio de Janeiro.

UNIRIO - Universidade Federal do Rio de Janeiro. 


\section{Lista de quadros}

Quadro 1 - Teses e Dissertações localizados no portal da CAPES

Quadro 2 - Organização da oferta de Educação Infantil na rede pesquisada

Quadro 3 - Demonstrativo da situação dos PPPs das escolas

Quadro 4 - Número de Escolas que informaram sobre os PPPs

Quadro 5 - Situação dos PPPs informados das Escolas de/com Educação Infantil

Quadro 6 - Organização das turmas da Escola A em 2014

Quadro 7 - Organização das turmas da Escola A em 2015

Quadro 8 - Datas e ações relacionadas

Quadro 9 - Organização das turmas de Educação Infantil da Escola B em 2014

Quadro 10 - Organização das turmas de Educação Infantil da Escola B em 2015

Quadro 11 - Perfis das Professoras envolvidas com a pesquisa 